\title{
Scurvy in the Context of End-Stage Liver Disease
}

Amiirah Aujnarain MSc, Michael Hackett CD CCPA, Kumanan Wilson MD MSc

\begin{abstract}
About the Authors
Amiirah Aujnarain is a member of the Faculty of Medicine. Michael Hackett and Kumanan Wilson are members of the Division of General Internal Medicine, and Kumanan Wilson is also a member of the Department of Medicine, Ottawa Hospital Research Institute. All are at the University of Ottawa, in Ottawa, Ontario. Correspondence may be directed to kwilson@ohri.ca.
\end{abstract}

\section{Summary}

The authors present a case of scurvy in a 38-year-old woman with a history of alcohol abuse and end-stage liver disease. Their case demonstrates that nutritional deficiencies are a concern in patients affected with alcoholic liver disease. The history, symptoms, and treatment of scurvy are also discussed.

\section{Résumé}

Les auteurs analysent un cas de scorbut chez une femme de 28 ans présentant des antécédents d'alcoolisme et atteinte de maladie hépatique terminale. Ils démontrent que les carences nutritionnelles sont problématiques chez un patient atteint de maladie hépatique chronique. Ils décrivent également l'histoire, les symptômes et le traitement du scorbut.

\section{Case}

A 38-year-old Caucasian female presented with coffee-ground emesis, melena, lethargy, malaise, jaundice, and confusion. The patient had a history of excessive alcohol use, cirrhosis, alcoholic hepatitis, progressive abdominal pain, and increasing scleral icterus. She had also had a polyneuropathy since 2009, presumed to be secondary to excess alcohol intake. Past medical history included fibromyalgia and possible systemic lupus erythematosus (SLE).

On admission, her blood pressure was $96 / 60 \mathrm{~mm} \mathrm{Hg}$, heart rate 115 beats per minute, respiratory rate 18 breaths per minute, and oxygen saturation $98 \%$ on room air, and she was normothermic. She was jaundiced, with blood in her mouth. Her abdomen was distended with bulging flanks but with no palpable liver or spleen. She had pitting edema to her sacrum. The neurological examination was consistent with the known peripheral sensory motor neuropathy. There was no bleeding of her nails and no corkscrew hair.

Initial blood work demonstrated a hemoglobin of $70 \mathrm{~g} / \mathrm{L}$, a white blood cell count of $17.2 \times 10^{9} / \mathrm{L}$, and a platelet count of $177 \times 10^{9} / \mathrm{L}$. Her electrolytes showed a sodium level of $119 \mathrm{mmol} / \mathrm{L}$, potassium $5.1 \mathrm{mmol} / \mathrm{L}$, chloride $89 \mathrm{mmol} / \mathrm{L}$, and carbon dioxide $20 \mathrm{mmol} / \mathrm{L}$. Creatinine and urea were 75 and $5.4 \mathrm{mmol} / \mathrm{L}$, respectively. Her International Normalized Ratio (INR) on admission was 2.7 (normal 0.9-1.2). The total bilirubin level was $193 \mu \mathrm{mol} / \mathrm{L}$ (normal 3-17 $\mu \mathrm{mol} / \mathrm{L}$ ). A subsequent indirect bilirubin level was 74 . Her level of alanine aminotransferase (ALT) was at $27 \mathrm{U} / \mathrm{L}$ (normal 17-63 U/L), aspartate aminotransferase (AST) 114 U/L (normal 15-37 U/L), Ү-glutamyl transpeptidase (GGT) 34 U/L (normal 5-55 U/L), alkaline phosphatase (ALP) 175 U/L (normal 50-136 $\mathrm{U} / \mathrm{L}$ ), and lipase $56 \mathrm{U} / \mathrm{L}$ (normal 73-393 U/L).

The patient was given two units of packed red blood cells, pantoprazole and octreotide for her upper gastrointestinal (GI) bleed, and ceftriaxone for possible spontaneous bacterial peritonitis. She had no further GI bleeds and received lactulose (titrated to three bowel movements per day) for hepatic encephalopathy. She received furosemide for peripheral edema, which was later switched to a potassium-sparing diuretic, and pentoxifylline for hepatitis.

The patient had progressive non-resolving anemia despite no obvious ongoing GI source. She also had a progressive peripheral neuropathy. Increasing non-conjugated hyperbilirubinemia led to the consideration of autoimmune hemolysis, and rheumatology was consulted to determine if this and her arthralgias were from SLE. Rheumatology found her to be positive for anti-smooth muscle antibody and antinuclear antibody (homogeneous pattern; titre of 1:160). They concluded that there was an autoimmune component to her symptoms and started her on steroids, but with minor improvement only. Neurology concluded that she had a severe generalized polyneuropathy following electromyographic 
studies that showed axonal loss and demyelination. She received low-dose hydromorphone for pain. Of note, the patient had continued gingival bleeding despite vitamin $\mathrm{K}$ administration and the normalization of her INR.

Many symptoms, such as the gingival bleeding, arthralgias, weakness, anemia, and jaundice, indicated the possibility of scurvy. Testing confirmed this suspicion, with vitamin C levels $<5 \mu \mathrm{mol} / \mathrm{L}$ (normal $>25 \mu \mathrm{mol} / \mathrm{L}$ ). However, oral vitamin $\mathrm{C}$ intake did not resolve her symptoms. Due to the possibility of malabsorption secondary to gut edema, IV vitamin C was started. Within days, the patient's muscle weakness improved, her hemoglobin stabilized, her arthralgias improved, and she had no further gum bleeding.

\section{Discussion}

Scurvy was first documented in $1500 \mathrm{BC}^{1}$; however, the etiology remained unclear until Sir James Lind conducted a study upon a ship where he treated affected soldiers and found the cure to be lemons and oranges. ${ }^{2}$ Scurvy is now known to result from a nutritional deficiency of vitamin $\mathrm{C}$ (ascorbic acid). In the developing world, the last significant outbreak was in 2002 in Afghanistan after a long drought. ${ }^{3}$ While infrequently diagnosed in the developed world, it is important to consider, especially for populations such as the elderly, alcohol abusers, drugs abusers, those who follow strict diets, those who have eating disorders, or those with malabsorption. ${ }^{4,5}$

Early symptoms are nonspecific: fatigue, weakness, weight loss, myalgias, arthralgias, and irritability. This makes the diagnosis of scurvy challenging. More identifiable symptoms take 1-3 months to appear. ${ }^{6}$ Vitamin C deficiency impairs collagen synthesis. Specifically, it promotes molecular crosslinking, which gives collagen its elasticity. Deficiency results in bleeding gums, joint pain, and petechiae. ${ }^{78}$ Rarely, there are cardiac changes including ST elevation and atrioventricular blocks. Left untreated, vitamin C deficiency can be fatal. ${ }^{9}$ Humans are unable to synthesize vitamin $\mathrm{C}$ or store it. Exogenous sources include fruits and vegetables. Fresh foods are needed as ascorbic acid deteriorates through cooking or storage. ${ }^{10}$

The effects of alcohol on ascorbic acid are poorly understood. Faizallah et al. conducted a small study in nine healthy male subjects. ${ }^{11}$ The study found that almost half of ascorbic acid was excreted within 4 hours of alcohol ingestion. Although this relationship requires further study, our case highlights scurvy's potential in alcohol abusers and the potential for late diagnosis due to non-specific signs and symptoms. Scurvy is important to recognize given its potentially fatal consequences, and the simplicity of treatment. Scurvy is cured with vitamin C administration. Currently, the daily recommended intake is $75 \mathrm{mg}$ for women and $90 \mathrm{mg}$ for men. ${ }^{12}$ For those with scurvy, $1-2 \mathrm{~g}$ of daily vitamin $\mathrm{C}$ is recommended for the first 3 days, then $500 \mathrm{mg}$ daily for 7 more days. After that, $100 \mathrm{mg}$ of vitamin $\mathrm{C}$ should be taken daily for 3 months. Fatigue, lethargy, pain, and confusion typically improve within 24 hours. Bruising, gingival bleeding, and weakness resolve within 2 weeks. Complete recovery should be expected within 3 months. ${ }^{13}$

For our patient, vitamin $\mathrm{C}$ deficiency explains several, but not all, of her signs and symptoms. Vitamin C deficiency likely caused her bleeding gums and nails and contributed to arthralgias, all of which improved with treatment. Her anemia was likely multifactorial. However, a component may have been from scurvy-induced intravascular hemolysis (which also explains the unconjugated hyperbilirubinemia). Her peripheral neuropathy was likely unrelated, although vitamin $\mathrm{C}$ deficiency has previously been associated with femoral nerve neuropathy. ${ }^{14}$

\section{References}

1. Pimentel L. Scurvy: historical review and current diagnostic approach. Am J Emerg Med 2003;21:328-32.

2. Stewart CP, Cuthrie D. Lind's Treatise on Scurvy. Edinburgh: Edinburgh University Press; 1953.

3. Cheung E, Mutahar R, Assefa F. An epidemic of scurvy in Afghanistan: assessment and response. Food Nutr Bull 2003;24:247-55.

4. Swanson AM, Hughey LC. Acute inpatient presentation of scurvy. Cutis 2010;86(4):205-7.

5. Maltos AL, Portari GV, Saldanha JC, et al. Scurvy in an alcoholic malnourished cirrhotic man with spontaneous bacterial peritonitis. Clinics 2012;67(4):405-7.

6. Hodges RE, Hood J, Canham JE, et al. Clinical manifestations of ascorbic acid deficiency in man. Am J Clin Nutr 1971;24:432-43.

7. Jacob RA, Sotoudeh G. Vitamin C function and status in chronic disease. Nutr Clin Care 2002;5(2):66-74.

8. Samonte VA, Sherman PM, Taylor GP, et al. Scurvy diagnosed in a pediatric liver transplant patient awaiting combined kidney and liver retransplantation. Pediatr Transplant 2008;12(3):363-7.

9. Francescone MA, Levitt J. Scurvy masquerading as leukocytoclastic vasculitis: a case report and review of the literature. Cutis 2005;76:261-6.

10. Olmedo JM, Yiannias JA, Windgassen EB, Gornet MK. Scurvy: a disease almost forgotten. Int J Dermatol 2006;45:909-13.

11. Faizallah R, Morris AI, Krasner N, Walker RI. Alcohol enhances vitamin C excretion in the urine. Alcohol 1986;21:81-4.

12. Carr AC, Frei B. Toward a new recommended dietary allowance for vitamin $\mathrm{C}$ based on antioxidant and health effects. Am J Clin Nutr 1999;69:1086-107.

13. Leger D. Scurvy: reemergence of nutritional deficiencies. Can Fam Physician 2008;54(10):1403-6.

14. Hood J. Femoral neuropathy in scurvy. N Engl J Med 1969;281:1292-3. 